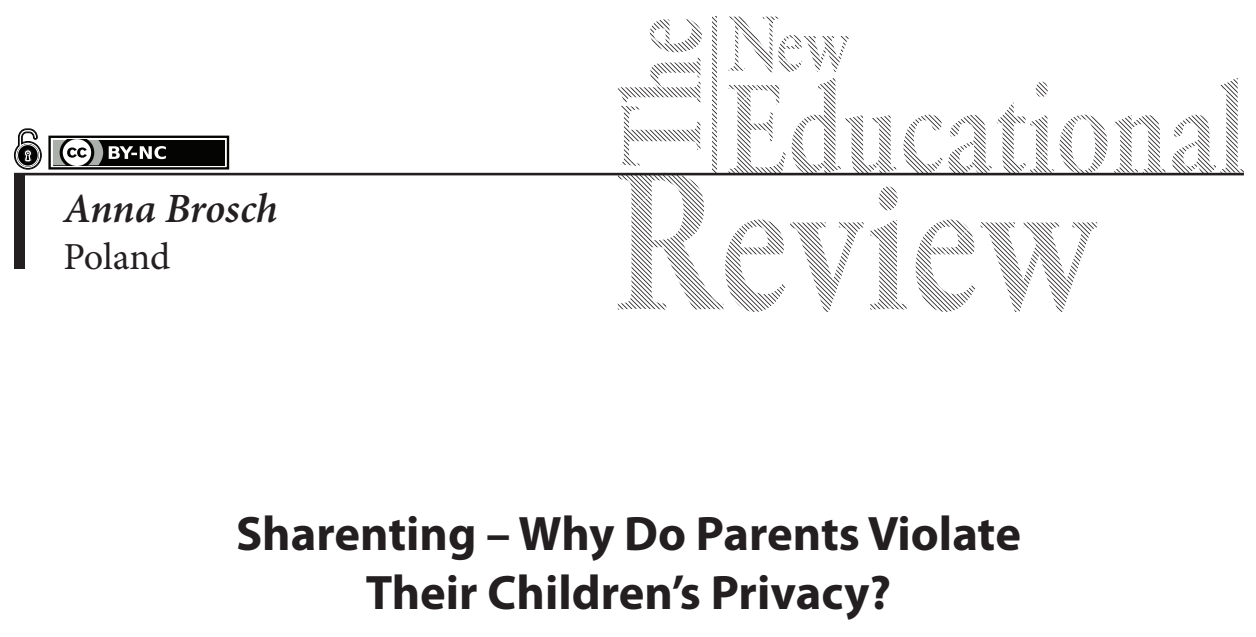

DOI: $10.15804 /$ tner.2018.54.4.06

\begin{abstract}
This paper presents a theoretical analysis of the concept of sharenting, emphasizing its role in violating children's privacy. Mechanisms of online self-disclosure are also analyzed, especially regarding parents' activities consisting of posting information about their children online. Lack of legal regulations regarding the protection of children's privacy online was also pointed out. Finally, a model of sharenting was developed, which was the basis for establishing a framework of the conceptualization of a research project on sharenting.
\end{abstract}

Keywords: children's privacy, self-disclosure, sharenting

\title{
Introduction
}

Social networking sites (SNSs) have become significant platforms for human interactions and the presentation of the Self in the sense of making public a personal image, narrative or description, which was featured high on the research agenda of cybercultural and digital media scholars (cf., Dominick, 1999; Cheung, 2000; Van Dijk., 2009). But very often parents use SNSs not only to share information about their own lives, but also to discuss their children's lives and share personal information about their children (Business Wire, 2010). The phenomenon of sharing and disclosing intimate information about children by their parents through SNSs is growing rapidly. Social networking sites, especially Facebook, are being flooded by a growing number of information and photos portraying 
children in different daily situations, even very intimate, e.g., sitting on the potty. Many new parents revel in posting silly and cute pictures of their infants online as an expression of affection. As an example, in the United States, $92 \%$ of children under the age of two have some sort of presence in the social media, and one-third make their debut online before they are one day old (Duggan, Lenhart, Lampe \& Ellison, 2015). According to AVG Technologies research conducted in 2010, on average, children acquire a digital identity by the age of six months (AVG Technologies, 2010). However parents very often shape their children's digital identity even before their birth, by posting sonogram images of their unborn children (Brosch, 2016).

The term "sharenting", coined from "share" and "parenting", neatly captures this activity. Thus, the question arises: How is it possible that parents violate their children's privacy so thoughtlessly? Perhaps it is a way in which parents celebrate the lives of their children, but on the other hand, nobody knows its consequences for the children in the future. Therefore, sharenting has become a subject of research by increasing numbers of scholars worldwide, but the knowledge of this phenomenon is still meagre.

\section{The motives of disclosing on social media}

Although there is a variety of different types of social networking sites (SNSs), e.g., Facebook, Twitter or MySpace, in fact each of them offers users a unique opportunity to communicate with a large number of people without the need to invest too much time or effort. Therefore, researchers identify several benefits connected with disclosing information about private life on SNSs. A number of studies have indicated the convenience of establishing and maintaining relationships as one of the most important benefits from online self-disclosure (cf., Hui, Tan \& Goh, 2006; Gibbs, Ellison \& Heino, 2006; Cheung, Lee \& Chan, 2015). Building and supporting new relationships is certainly connected with the need for accumulating social capital (Ellison, Steinfield, \& Lampe, 2007). A significant element of participation in SNSs is also the possibility of self-presentation by sharing photos, belonging to different groups or building communities based on similar interests (Boyd, 2007; Gibbs et al., 2006). This active self-disclosing behavior can also be of hedonistic nature, based on intrinsic motivation referring to "doing something because it is inherently interesting or enjoyable" (Ryan \& Deci, 2000, p. 55). Some authors argue that enjoyment is more powerful than perceived usefulness (Krasnova, Spiekermann, Koroleva \& Hildebrand 2010). According to traditional 
interpersonal communication theory such as social penetration theory, there is a linear increase in the breadth and depth of self-disclosure over time (Altman \& Taylor, 1973). In this regard, SNS users present themselves through photos, stories, etc., expecting that their SNS friends will do the same to deepen their familiarity. In other words, this reciprocal process of self-disclosure is expected to increase intimacy between SNS users.

Self-disclosure is usually measured taking into account two dimensions - the breadth and depth of shared information. The breadth refers to the amount of disclosed information, which includes the frequency and duration of disclosed contents, whereas the depth reflects the level of intimacy, which is associated with the user's honesty, accuracy and intention (Wheeles \& Grotz, 1976).

With regard to sharenting, research has shown that while parents have concerns about their children's privacy, they still see benefits from sharing information about them because of the social support they receive (Kumar \& Schoenebeck, 2015). Social networking sites allow parents to share their own experiences with parenting, through answering questions and sharing information about their own children. But on the other hand, their children are growing up with a conviction that sharing personal details is natural practice. Thus, when they become parents in the future, they will incline even more to self-disclosure than their parents (Brosch, 2016). However, still little is known about parents' underlying decision process, which makes them share details about their children's life and also their strategies to diminish the risks for their children.

\section{Sharenting - the definition problem}

Undoubtedly, defining terms is one of the most thankless tasks in science, because a few always will have a different view on a given problem or find the definition in some way wanting. However, clarification of a term is of considerable value in avoiding confusion among scholars investigating the same, or similar, phenomena and is necessary in the development of theory, as well.

Taking into account the term "sharenting," researchers attempt to establish parents' motives or range of activities connected with disclosing information about children, rather than focus on the true essence of the phenomenon being defined. Moreover, they usually rely on dictionary definitions or do not define it at all. It must be emphasized that in dictionaries the term "sharenting" is defined so generally that no element indicate directly what this phenomenon actually is. For example, in Collins Dictionary "sharenting" is defined as "the habitual use of social 
media to share news, images, etc., of one's children" (Collins Dictionary online). Urban Dictionary defines "sharenting" in a similar way: "When parents share too much of their children's information, pictures and private moments online, mostly on Facebook" (Urban Dictionary online). Thus, based on these definitions, scholars define "sharenting" usually as "a term used to describe the ways many parents share details about their children's lives online" (Steinberg, 2017). This way of defining "sharenting", although used in many sources (e.g., Blum-Ross, Livingstone, 2017; Steinberg, 2017), is so general and vague that it serves little scientific purpose and rises some doubts. As rightly pointed out by Phoebe Maltz Bovy, two criteria need to be met to talk about sharenting: the presence of a mass audience and the possibility of identifying the child (2013). In fact, sharenting does not refer to communication between family members or friends, even if parents share with them an enormous amount of information or pictures connected with their children. Sharenting does not also deal with anonymous sharing of information or photos concerning children, because in this case the recognition of the child is impossible. One more important factor should be taken into consideration during defining the term "sharenting" - the possible risk for children. Some researchers report new phenomena as consequences of sharenting, such as digital kidnapping (O’Neill, 2015) or online pedophilia (Durkin \& Bryant, 1999; Jenkins, 2001), but in fact sharenting is seldom associated with such tragic circumstances. But there is no doubt that parents in this way infringe their children's right to privacy, which can put them in danger now and in the future. Obviously, today it is impossible to predict the consequences of such a kind of parents' activity. Anyway, the fundamental risk of sharenting is associated with losing privacy by the child. What is more, by posting news about their child online parents lose their ability to control its future fate.

Taking the above into account, the term "sharenting" should be defined as: Making public by parents a lot of detailed information about their children in the form of photos, videos and posts through social media, which violate children's privacy.

\section{Towards a model of sharenting}

Sharenting basically concerns publicizing a large amount of information. However, in many cases it is enough to post only one inappropriate photo to humiliate the child. Is that sharenting then, or not? For example, in April, 2017, the court ruled the first judgment on sharenting in Poland. A father was sentenced to 3 months' imprisonment for posting only one photo of his son on Facebook. In this 
photo, the naked 2 years old boy was holding a bottle of beer in one hand and his genitals in the other (Szczurowska, 2017). This shows how important not only the amount is but also the content of the posted information. Moreover, the questions arise: How much information needs to be posted to speak about sharenting? After all, thousands of photos showing a child's everyday life posted on the Web will not hurt the child as much as only one embarrassing picture. Moreover, should this activity be characterized by regularity or is posting hundreds of photos at once enough? And finally, how to measure the level of sharenting? It seems that to measure the level of sharenting, four dimensions should be taken into account: the amount, frequency, content and viewers of the posted information about the child. The total score of these dimensions can determine the level of sharenting, which will allow for comparing parents with respect to their level of sharenting.

The amount and frequency of posted information allows for establishing the level of parents' activity in sharenting. In this case, the form of this information is not important, although there is no doubt that posting photos of children is the most popular activity in this field.

By analyzing the content of posted information, it is possible to establish the level of intimacy of the disclosed information. As shown by research, the information about children disclosed by parents ranged from lighthearted anecdotes, through reports of their everyday life to disclosing the children's secrets or embarrassing them (Steinberg, 2017; Jomhari, Gonzalez \& Kurniawan, 2009; Brosch, 2016). This information can determine the child's well-being in the future. As Bovy emphasizes: "A child might sympathize with writing about his illness, but not about that time when he was three and wet the bed" (2013). However, sometimes not the picture itself can ridicule a child, but the commentary on it. For example, one mother posted on Facebook a picture of her baby, whose face was grimed with a brown substance (chocolate). Maybe such a photo seems to be funny, but the comment on it written by one of the users - I hope it's chocolate! - simply ridicules the child.

The last dimension of sharenting concerns the audience. It is associated with the number of friends on SNSs and profile privacy settings, which can establish who in fact can watch posted information. Sharenting basically refers to invisible audience. Public accounts allow everyone, undoubtedly, to see posted contents. However, even limiting the audience to the friends very often is not enough, because it is impossible to be a close friend with thousands of people from the contact list.

To summarize, the model of sharenting includes four elements: the amount, frequency, content of posted information and the audience. Only insightful anal- 
ysis of these dimensions allows for establishing the true level of sharenting and classifying parents with regard to their tendency to disclose information about their children online.

\section{Children's right to privacy}

As the topic of privacy is of considerable interest to a wide variety of disciplines, there is extensive literature on this issue. However, the term "privacy" is very difficult to define. As Judith Jarvis Thomson has rightly pointed out, "the right to privacy is that nobody seems to have any very clear idea what it is" (Thomson, 1975, p. 295). Irwin Altman emphasizes the role of privacy in the interpersonal boundary control process (Altman, 1976, p. 7). Alan Westin (1967) defines privacy as "the claim of individuals, groups, or institutions to determine for themselves when, how and to what extent information about them is communicated to others" (p. 7). In general, privacy is associated with the possibility of using different patterns of verbal and nonverbal mechanisms to make themselves more or less accessible to others.

Thus, privacy is determined by two opposite poles - the need to withhold information about oneself to prevent the loss of privacy on the one hand, and the need for self-disclosure to maintain social relationships with others. In the online environments, this tension between these two poles has become more salient than ever. Adam N. Joinson indicates that the sense of anonymity is the key factor of disclosing online, which allows users greater freedom in expressing thoughts and feelings (Joinson, 2001).

What is more, this issue is much more complicated with regard to children's privacy. Currently, in most countries (cf., Kumar \& Schoenebeck, 2015; Steinberg, 2017), including Poland, no policy secures children's right to online privacy, leaving in the parent's hands the decision what kind of information about their children can be shared. From the Polish legal standpoint, children under 13 years of age do not have legal capacity, so they cannot make decisions whether and what kind of information about them can be shared online. What is more, they also cannot create an account on SNSs.

As parents are the gatekeepers of personal information of their children, they are obliged to protect their children from harm online (COPPA, 2012). But on the other hand, only parents are allowed to decide whether and how much information will be contributed to SNS. Therefore, although parents are the first line of defense to protect their children's privacy, in many cases they are not indeed (Keenan, 
2012). What is more, when parents share information about their children online, they do so without their children's consent. From the age of 13 , the child has a right to decide whether and what kind of their personal information can be shared online by parents.

\section{$\underline{\text { Planned research project on sharenting }^{1}}$}

The aim of the planned project is to determine the relationship between the level of sharenting and parents' tendency to self-disclosure, as well as their age, sex and activity on Facebook. As the high level of self-disclosure can give parents a sense that "privacy is no longer a social norm" (Johnson, 2010), it will be considered as a key factor of sharenting.

The first step was to define the concept of sharenting and determine its aspects, such as form, amount, content and frequency of posted information, which was discussed in the section above. Based on the points assigned to each activity, it will be possible to specify the level of sharenting. To evaluate the level of parents' self-disclosure, a Self-disclosure Questionnaire will be developed, consisting of 3 subscales. It will provide the total score of the self-disclosure level and three subscores referring to different levels of the depth (intimacy) of shared information. The all-Poland research will be conducted among approx. 1000 parents of children at preschool age. To select a representative sample of the population, a cluster random sampling will be used, where clusters will be all kindergartens in Poland.

As every research project, also this one is subject to limitations. Firstly, the research sample will consist of parents of children at pre-school age living in Poland. By doing so, parents of children under 3 will be excluded, although in fact this group of children is the most frequently at risk of sharenting. This limitation is caused by accessibility of parents. As the planned research will be all-Poland, it is only possible to select a sample of parents whose children attend kindergarten. After all, it is virtually impossible to reach parents outside the kindergarten when research is conducted on such a large scale.

As previous research did not provide adequate insights into the true extent of sharenting and its relationship with such variables as age, sex, activity on Facebook

1 This research is supported by the National Science Centre, Poland. Project titled: Zakres i uwarunkowania zjawiska "sharenting" wśród rodziców na portalu społecznościowym Facebook/The range and causes of the "sharenting" phenomenon among parents on Facebook/. No. 2017/01/X/HS6/00612. 
and, above all, the level of parents' self-disclosure, a quantitative approach will be adopted, which is associated with the positivist paradigm. This constitutes the second limitation of the project. Unlike qualitative methods, quantitative research does not allow for finding the deeper meaning of parents' behavior. But given that sharenting is still an emerging phenomenon in research, quantitative research with its generalizability allows for statistical calculations and drawing conclusions. Thus, statistical analysis will make it possible to discover complex causal relationships and to determine to what extent individual variables influence the level of sharenting.

\section{Conclusion}

Information shared on the Internet has the potential to remain long after posting it without senders' control. Therefore, disclosures made during childhood may have a potential influence on the children's future lifetime. As pointed out in this paper, parents are obligated to protect their children's privacy online, but in many cases their online activity has an opposite effect. While existing research provides some valuable insights into specific determinants of sharenting, parents still seem to be unaware of the consequences of their openness online. So, in the absence of other protection, also the media have a responsibility for publishing material that could damage a child's long-term personal or professional prospects.

Although significant progress has been made in the scientific studies on the phenomenon of sharenting so far, it is not enough and the question of why parents exhibit their children online is still open. Therefore, research planned within the project will partially fill in this gap and make a useful contribution to the field of social science.

\section{Acknowledgment}

The publication has been prepared as part of the project titled: Zakres i uwarunkowania zjawiska "sharenting" wśród rodziców na portalu społecznościowym Facebook /The range and causes of the "sharenting" phenomenon among parents on Facebook/, financed by the National Science Centre, Poland. No. 2017/01/X/HS6/00612. 


\section{References}

Altman, I. \& Taylor, A. (1973). Social penetration: the development of interpersonal relationships. New York: Holt, Rinehart \& Winston.

Altman, I. (1976). Privacy: A Conceptual Analysis, Environment and Behavior, 8(1), pp.7-30.

AVG Technologies (2010). AVG Digital Diaries: Digital Birth. Retrieved 12/10/2018, from http://www.avgdigitaldiaries.com/post/6874613434/digital-birth-research-results-and-reflections

Blum-Ross, A. \& Livingstone, S. (2017). Sharenting, parent blogging, and the boundaries of the digital self. Popular Communication, 15(2), pp. 110-25

Boyd, D. (2007). Why Youth (Heart) Social Network Sites: The Role of Networked Publics in Teenage Social Life. In: D. Buckingham (Ed.). Youth, Identity, and Digital Media. Cambridge: MIT Press, pp.119-142.

Brosch, A. (2016). When the Child is born into the Internet: Sharenting as a growing trend among parents on Facebook. The New Educational Review, 43(1), pp. 225-235. ISSN: $1732-6729$.

Business Wire (2010). Digital Birth: Welcome to the Online World. Retrieved 12/10/2018, from http://www.businesswire.com/news/home/20101006006722/en/Digital-Birth-Online-World .

Cheung, C. (2000). A Home on the Web: Presentations of Self on Personal Homepages. In: D. Gauntlett (Ed.), Web. Studies - Rewiring media studies for the digital studies. London: Arnold.

Cheung, C., Lee, Z.W.Y. \& Chan, T.K.H. (2015). Self-disclosure in social networking sites: The role of perceived cost, perceived benefits and social influence. Information Research, 25(2), pp. 279-300.

Children's Online Privacy Protection Act (COPPA), 15 U.S.C. 6501-6506 (2012).

Dominick, R.J. (1999). Who Do You Think You Are? Personal Home Pages and Self-Presentation on the World Wide Web. Journalism \& Mass Communication Quarterly, 76(4), pp. 646-658.

Duggan, M., Lenhart, A., Lampe, C. \& Ellison, N.B. (2015). Parents and Social Media. Pew Research Center. Internet \& Technology. Retrieved 1/10/2018, from http://www. pewinternet.org/2015/07/16/parents-and-social-media/

Durkin, K.F. \& Bryant, C.D. (1999). Propagandizing pederasty: A thematic analysis of on-line exculpatory accounts of unrepentant pedophiles. Deviant Behavior, 20, pp. 103-127.

Ellison, N.B., Steinfield, C. \& Lampe, C. (2007). The benefits of Facebook "friends:" Social capital and college students' use of online social network sites. Journal of Computer-Mediated Communication 12(4), pp. 1143-1168.

Gibbs, J.L., Ellison, N.B. \& Heino, R.D. (2006). Self-Presentation in Online Personals, Communication Research, 33(2), pp. 152-177.

Hui, K-L., Tan, B.C.Y. \& Goh, C-Y. (2006). Online Information Disclosure: Motivators and Measurements, ACM Transactions on Internet Technology 6(4), pp. 415-441 
Jenkins, P. (2001). Beyond tolerance: Child pornography on the Internet. New York: New York University Press.

Johnson, B.(2010). Privacy no longer a social norm, says Facebook founder. The Guardian. Retrieved 22/10/2018, from http://www.theguardian.com/technology/2010/jan/11/ facebook-privacy

Joinson, A.N. (2001). Self-disclosure in computer-mediated communication: The role of self-awareness and visual anonymity. European Journal of Social Psychology, 31, pp. 177-192.

Jomhari, N., Gonzalez, V.M. \& Kurniawan S.H. (2009). See the apple of my eye: baby storytelling in social space. In: Celebrating People and Technology. Proceedings of HCI 2009. A. Blackwell (Ed.). Churchill College Cambridge, United Kingdom. pp. 238-243. Retrieved 19/12/2015, from http://www.bcs.org/upload/pdf/ewic_hci09_paper29.pdf.; Keenan, J. (2012). Thanks, Mom, for Not Telling the World I Pulled a Knife on You. The New York Times. Retrieved 19/10/2018, from https://parenting.blogs.nytimes. com/2012/12/27/thanks-mom-for-not-telling-the-world-i-pulled-a-knife-on-you/

Krasnova, H., Spiekermann, S., Koroleva, K. \& Hildebrand, T. (2010). Online social networks: Why we disclose. Journal of Information Technology, 25(2), pp. 109-125, DOI: 10.1057/jit.2010.6

Kumar, P. \& Schoenebeck, S. (2015). The modern day baby book: Enacting good mothering and stewarding privacy on Facebook. In Proceedings of the $18^{\text {th }}$ ACM Conference on Computer Supported Cooperative Work \& Social Computing, ACM, pp. 1302-1312.

Maltz Bovy, P. (2013). The Ethical Implications of Parents Writing About Their Kids. The Atlantic. Retrieved 10/10/2018, from http://www.theatlantic.com/sexes/archive /2013/01/the-ethical-implications-of-parents-writingabout-their-kids/267170/ .

O’Neill, J. (2015). The Disturbing Facebook Trend of Stolen Kids Photos, March 3, Retrieved 19/12/2017, from https://www.yahoo.com/parenting/mom-my-son-was-digitally-kidnapped-what-112545291567.html

Ryan, R.M. \& Deci, E.L. (2000). Intrinsic and Extrinsic Motivations: Classic Definitions and New Directions. Contemporary Educational Psychology, 25, pp. 54-67, DOI:10.1006/ ceps.1999.1020.

Sharenting. In: Collins Dictionary. Retrieved 1/08/2018, from https://www.collinsdictionary.com/dictionary/english/sharenting

Sharenting. In: Urban Dictionary. Retrieved 1/08/2018, from https://www.urbandictionary. com/define.php?term=Sharenting

Steinberg, S.B. (2017), Sharenting: Children's Privacy in the Age of Social Media. Emory Law Journal, 839(66), pp. 839-884.

Szczurowska, M. (2017), Pierwszy w Polsce wyrok za umieszczanie kompromitujących zdjęć dzieci na Facebooku /The first sentence in Poland for posting embarrassing photos of children on Facebook/. SocialPress. Retrieved 19/10/2018, from https://socialpress. pl/2017/04/pierwszy-w-polsce-wyrok-za-umieszczanie-kompromitujacych-zdjec-dzieci-na-facebooku.

Thomson, J.J. (1975). The Right to Privacy, Philosophy \& Public Affairs, 4, pp. 295-314. 
Van Dijk J.A.G.M. (2009). Users like you? Theorizing agency in user-generated content. Media, Culture \& Society, 31(1), pp. 41-58.

Westin, A. (1967). Privacy and Freedom. New York: Atheneum.

Wheeless, L.R. \& Grotz, J. (1976). Conceptualization and measurement of reported self-disclosure. Human Communication Research, 2(4), pp. 338-346. 